\title{
Can a self-management education program for patients with chronic obstructive pulmonary disease improve quality of life ?
}

\author{
Manon Labrecque MD MSc, Khalil Rabhi PhD, Catherine Laurin PhD, \\ Helene Favreau PhD, Gregory Moullec PhD, Kim Lavoie PhD, Marcel Julien MD
}

M Labrecque, K Rabhi, C Laurin, et al. Can a self-management education program for patients with chronic obstructive pulmonary disease improve quality of life? Can Respir J 2011;18(5):e77-e81.

OBJECTIVE: To assess the effects of a self-management program on health-related quality of life (HRQoL) and morbidity commonly associated with chronic obstructive pulmonary disease (COPD).

METHODS: A total of 57 outpatients with stable COPD received four weeks of self-management education, while 45 patients received usual care. Patients were evaluated at baseline, at three months and one year following the educational intervention. The primary outcome variable was HRQoL measured by the St George's Respiratory Questionnaire (SGRQ). The secondary outcome variables were number of emergency room visits and hospitalizations for exacerbation.

RESULTS: The intervention group's HRQoL improved significantly at three months (total score $\mathrm{A}=-5.0[\mathrm{P}=0.006]$ ) and 12 months (total score $\mathrm{A}=-6.7[\mathrm{P}<0.001])$, as evidenced by decreased scores on the SGRQ. In contrast, the SGRQ scores increased significantly in the control group at three months (total score $\mathrm{A}=+3.7[\mathrm{P}=0.022]$ ) and 12 months (total score $\mathrm{A}=+3.4[\mathrm{P}=0.032])$. Global impact appeared to be responsible for the change in the intervention group. Moreover, in the intervention group, the number of hospitalizations dropped from $0.7 /$ person/year to $0.3 /$ person/year $(\mathrm{P}=0.017)$, and emergency room visits dropped from 1.1 person/year to $0.2 /$ person/year $(\mathrm{P}=0.002)$, while subjects in the control group did not experience any significant decreases in these parameters.

CONCLUSIONS: A planned education program improved HRQoL while decreasing the number of emergency room visits and hospitalizations in patients with stable COPD; this improvement persisted at 12 months.

Key Words: COPD; Quality of life; Self-management education
Un programme d'éducation à l'autogestion pour les patients atteints d'une maladie pulmonaire obstructive chronique améliore-t-il la qualité de vie?

OBJECTIF : Évaluer les effets d'un programme d'autogestion sur la qualité de vie liée à la santé (QVLS) et sur la morbidité souvent associée à la maladie pulmonaire obstructive chronique (MPOC).

MÉTHODOLOGIE : Au total, 57 patients en consultations externes ayant une MPOC stable ont reçu une éducation à l'autogestion de quatre semaines, tandis que 45 patients ont reçu les soins habituels. Les patients ont été évalués au départ, puis trois mois et un an après l'intervention d'éducation. La variable d'issue primaire était la QVLS mesurée selon le questionnaire respiratoire de St George (QRSG). Les variables d'issue secondaire étaient le nombre de consultations à l'urgence et d'hospitalisations en raison d'exacerbations.

RÉSULTATS : La QVLS du groupe d'intervention s'est considérablement améliorée au bout de trois mois (indice total $\mathrm{A}=-5,0[\mathrm{P}=0,006]$ ) et de 12 mois (indice total $\mathrm{A}=-6,7[\mathrm{P}<0,001]$ ), tel que le démontre la diminution des indices au QRSG. Par contre, les indices du QRSG ont augmenté de manière significative dans le groupe témoin au bout de trois mois (indice total $\mathrm{A}=+3,7[\mathrm{P}=0,022]$ ) et de 12 mois (indice total $\mathrm{A}=+3,4[\mathrm{P}=0,032]$ ). L'impact global semblait être responsable de la modification dans le groupe d'intervention. De plus, dans ce même groupe, le nombre d'hospitalisations a fléchi de 0,7 par personne par année à 0,3 par personne par année $(\mathrm{P}=0,017)$, et les consultations à l'urgence sont passées de 1,1 par personne par année à 0,2 par personne par année $(\mathrm{P}=0,002)$, tandis que les sujets du groupe témoin ne présentaient aucune diminution significative de ces paramètres.

CONCLUSIONS : Un programme d'éducation planifié améliorait la QVLS tout en réduisant le nombre de consultations à l'urgence et d'hospitalisations chez les patients atteints d'une MPOC stable. Cette amélioration persistait au bout de 12 mois.

in these situations can benefit from self-management education programs that include an action plan but does not include a formal exercise program has not been widely documented.

Self-management is also a term applied to educational programs aimed at the teaching skills needed to perform medical regimens specific to the disease, guide health behaviour change, and provide emotional support for patients to control their disease and lead more functional lives.

An updated Cochrane meta-analysis on the effect of education in adults with COPD (9) concluded that self-management education is associated with a reduction in hospital admissions, with no evidence of detrimental effects on other outcome parameters. In the present Cochrane review, 15 group comparisons drawn from 14 trials were examined. They assessed a broad spectrum of interventions and health outcomes with different follow-up times. The studies showed a significant reduction in the probability of at least one hospital admission among patients receiving self-management education compared with those receiving usual care (OR 0.64 [95\% CI 0.47 to 0.89]). On the disease-specific St George's Respiratory Questionnaire (SGRQ), differences reached statistical significance on the total score (weighted mean difference [WMD] -2.58 [95\% CI -5.14 to -0.02$]$ ) and impact 
domain (WMD -2.83 [95\% CI -5.65 to -0.02]), but these differences did not reach the clinically relevant improvement threshold of 4 points. A small but significant reduction was detected in dyspnea measured using the Borg scale (WMD -0.53 [95\% CI -0.96 to -0.10$]$ ). No significant effects were found among the number of exacerbations, emergency department (ED) visits, lung function, exercise capacity or days lost from work. Inconclusive results were observed in doctor and nurse visits, on symptoms other than dyspnea, the use of oral corticosteroids and antibiotics, and the use of rescue medication. However, the authors noted that because of the interventions' heterogeneity in terms of study populations, follow-up times and outcome measures, the data were still insufficient to formulate clear recommendations regarding the form and content of self-management education programs for patients with COPD.

In a multicentre, randomized study including seven centres in Quebec published in 2003, Bourbeau et al (10) demonstrated that patients who were taught self-management techniques experienced $17 \%$ fewer exacerbations and $27 \%$ less hospital use than those receiving usual care in the year following the program. In this study, each patient randomly assigned to the intervention group received a diseasespecific self-management program ("Living Well with COPD" [Boehringer Ingelheim, Canada]) consisting of approximately $1 \mathrm{~h}$ per week of teaching at home for eight weeks. The program was supervised by experienced health professionals who acted as case managers under the supervision of the treating physician. Follow-up was conducted with patients in the intervention group by way of weekly telephone calls for a period of eight weeks (educational period) and, subsequently, monthly calls for the remainder of the study. Case managers were made available by telephone only to the intervention group for advice and treatment supervision throughout the study period.

The program developed at the Hôpital du Sacré-Coeur de Montreal (Montreal, Quebec) in 2004 is quite different. Instead of home-based individual care, it is a group program conducted at the hospital. In contrast to the Bourbeau et al (10) study, patients included in the intervention group did not receive regular telephone calls during the follow-up period, and no dedicated case managers were assigned to their care. Briefly, it is a self-management education program consisting of 10 patients per group who are provided with a half-day $(3 \mathrm{~h})$ training session per week for four consecutive weeks. The education program provides patients with a thorough understanding of COPD, and with an action plan and other information needed for the effective self-management of their symptoms.

Although patients were encouraged by the educator to exercise at home, this program contained no formal rehabilitation component. Moreover, patients were encouraged to identify a clinical resource to call (eg, their chest or family physician, their nurse or inhalotherapist from their CLSC [Centre local de services communautaires]) in case of questions regarding their action plans at the time of an exacerbation.

The aim of the present study was to examine the efficacy of this structured, self-management educational intervention on HRQoL, self-reported COPD knowledge and COPD morbidity (health care use) commonly associated with the disease. We prospectively studied a cohort of 102 COPD patients over a 12-month period, 57 of whom received the intervention, and 45 of whom were provided with usual care.

\section{METHODS}

The present analysis was a parallel group, prospective study. The patients were recruited between January 2004 and December 2004 in the pulmonary outpatient clinic of the Hôpital du Sacré-Coeur de Montreal. Patients in the intervention group were referred to the selfmanagement education program following a previous ED admission or hospitalization for COPD, or following a visit to an outpatient clinic. A control group comprised of stable COPD outpatients who were followed by a respirologist, but who were not referred to any selfmanagement education program at the time of the inclusion, served as a comparison group with an assurance to be included in the program at the end of the study. Patients were assessed at baseline (before the educational program), immediately after the intervention, at three months and at one year. All patients gave their informed, written consent. The present project was approved by the Human Ethics Committe of the Hôpital du Sacré-Coeur de Montreal.

\section{Patient selection}

Eligible patients were men or women 40 to 75 years of age who had been diagnosed with COPD by a chest physician according to American Thoracic Society criteria (11). All patients met the spirometry criteria for Global Initiative for Chronic Obstructive Lung Disease (GOLD) severity class 1, 2 or 3 (12). To be included in the study, all patients had to be able to read and write English or French, and have sufficient cognitive abilities to understand and complete the study assessments. In addition, they had to have never followed any previous COPD education program, and were not permitted to participate in any other educational or self-management programs for their COPD for the duration of the study. Finally, all patients were asked to maintain a stable maintenance medication regimen throughout the course of the study.

Patients were excluded if they had a comorbid illness that was more severe in nature and/or more debilitating than their COPD (eg, hepatitis, renal insufficiency requiring dialysis or untreated neoplasia). Other exclusion criteria were having recently (past three months) undergone surgery or an acute coronary event (eg, myocardial infarction). Intervention groups of 10 patients were provided with a weekly $3 \mathrm{~h}$ instruction session for four consecutive weeks. The content of the programs was based on 12 education modules created for patients with COPD by Boehringer-Ingelheim, ('Living Well with COPD'). There are four units in the sessions: anatomy, physiology and respiration mechanics; the breathing cycle and conservation of energy; signs and symptoms of COPD exacerbations; and an overview of action plans. In the final week of the program, patients received individualized counselling and instruction on the techniques related to the use of inhaled medications. A written action plan for acute exacerbations was customized for each patient. It emphasized the prompt initiation of an antibiotic with or without an oral corticosteroid for seven to 10 days after the onset of an exacerbation with infective symptoms; defined as at least two of the following three symptom changes: dyspnea, sputum, and sputum purulence lasting longer than $24 \mathrm{~h}$ (13). After the program, each subject was required to identify one contact person, a physician, a respiratory therapist or an educator, etc, to help them through their predefined action plan. The patients were responsible for having their prescriptions filled by their physician (general practitioner or specialist) and being available for study in case of symptomatic worsening. The patients were also given a sheet with simple and easy to understand bullet points regarding the most important functions in symptom monitoring.

\section{Measurements and outcomes}

Evaluation visits were scheduled at the study centre at enrollment (ie, initial visit), immediately after completion of the educational program, at four weeks, and at three months and 12 months. To minimize bias, patients were asked not to discuss their group assignment with the research assistant. Research assistants had no contact with participants other than during the evaluations.

\section{Primary outcome variable}

The prespecified primary outcome variable was the change in the domains of the SGRQ at three and 12 months.

\section{Secondary outcome variables}

Secondary outcome variables included the patient's knowledge of COPD at three and 12 months, health care use and number of COPD exacerbations at three and 12 months. 


\section{SGRQ}

The SGRQ, which has been used extensively in previous studies, is a disease-specific instrument designed to measure the impact of respiratory symptoms on overall health, daily life and perceived well-being (refer to reference 14 for validity and reliability). A negative difference is interpreted as an improvement. For the total SGRQ scores and each of the three SGRQ domains (symptoms, activity and impact), scores range from 0 to 100 , with higher scores representing worsening. A difference of greater than 4.0 is considered to be clinically important.

\section{COPD Knowledge Questionnaire}

The COPD Knowledge Questionnaire was specifically developed for the present study. It is simply a test to examine recall of the material presented in the program. It had four different sections, each comprising five questions related to each part of the educational program. A total score was calculated for each patient. The questionnaire was administered after the educational intervention (visit 2), and subsequently at three months (visit 3) and 12 months (visit 4) after the intervention. The COPD Knowledge Questionnaire was previously tested at our centre on a sample of 30 patients. A paired $t$ test indicated that the level of COPD knowledge as measured by our questionnaire significantly increased following an educational intervention $(\mathrm{P}=0.001)$. Furthermore, a test-retest analysis confirmed that the questionnaire results were consistent over time $(r=0.84)$. The instrument has shown good reliability, with a Cronbach's alpha score of 0.76 .

\section{Health care use}

COPD exacerbations were evaluated by questionnaire and medical chart review. The research assistant gathered information about the number of severe (ie, inpatient treated) COPD exacerbations at visits 3 and 4 (three- and 12-month follow-ups). A severe exacerbation was defined as an ED visit or hospitalization, and was self-reported by the patient. The reported events were verified by medical charts and reviewed by a blinded adjudication committee (two independent chest physicians not included in the study separately reviewed the medical charts and confirmed COPD exacerbation relatedness). Events reported by patients and not documented in the files were not considered. Outpatient exacerbations were also not considered (ie, those treated on an outpatient basis with pharmacotherapy) due to the difficulties in verifying such events.

\section{Statistical analysis}

A sample size of 65 patients per group was calculated to be adequate to detect a change of 4 points with $80 \%$ power on the SGRQ total score in the comparison group at a significance level of 0.05 (two-sided test) - a range of change that is considered to be clinically significant. For SGRQ score, the data were analyzed with a single repeated measures ANOVA after verifying that they met normality criteria. Repeatedmeasures ANOVA and Bonferroni correction for multiple tests were used to examine differences between time points in subjects who did and did not undergo the intervention, followed by paired $t$ tests to examine changes within each group. The Student's $t$ test, the Wilcoxon signed-rank test and the Mann-Whitney test were used to analyze differences between the intervention and control groups for dependent variables such as the scores on the COPD Knowledge Questionnaire, the number of hospitalizations for COPD and number of visits to an ED. All values are expressed as mean and 95\% CI. Statistical significance was set at $\mathrm{P}<0.05$, and all analyses were conducted using SPSS version 16.0 (SPSS Inc, USA) for Windows (Microsoft Corporation, USA).

\section{Study patients}

There were 60 patients enrolled in the intervention group and 50 in the control/treatment-as-usual group. Fifty-seven of the intervention patients and 45 control group subjects were available for follow-up at
TABLE 1

Baseline characteristics of the two study groups

\begin{tabular}{lccc}
\hline & \multicolumn{2}{c}{ Group } & \\
\cline { 2 - 3 } Characteristic & $\begin{array}{c}\text { Intervention } \\
(\mathbf{n}=\mathbf{5 7})\end{array}$ & $\begin{array}{c}\text { Control } \\
(\mathbf{n}=\mathbf{4 5})\end{array}$ & $\mathbf{P}$ \\
\hline Age, years & $69.12 \pm 8.5$ & $71.7 \pm 8.0$ & 0.07 \\
Ratio, men to women & 1.4 & 0.9 & 0.18 \\
FEV ${ }_{1}, \%$ predicted & $48.8 \pm 16.8$ & $57.9 \pm 25.7$ & 0.09 \\
Comorbidities & $2.3 \pm 1.7$ & $2.3 \pm 2.1$ & 0.70 \\
Smoking, pack-years & $42.3 \pm 24.4$ & $44.2 \pm 27.4$ & 0.60 \\
Baseline SGRQ score & & & \\
$\quad$ Symptoms & $26.3 \pm 14.8$ & $25.4 \pm 12.4$ & 0.74 \\
$\quad$ Activity & $64.4 \pm 18.9$ & $67.9 \pm 22.1$ & 0.39 \\
$\quad$ Impact & $33.3 \pm 17.5$ & $37.2 \pm 19.3$ & 0.28 \\
$\quad$ Total & $41.5 \pm 15.2$ & $44.5 \pm 17.2$ & 0.35 \\
Baseline COPD knowledge & $57.5 \pm 12.6$ & $57.6 \pm 15$ & 0.93 \\
$\quad$ score & & & \\
Hospitalizations in previous & $0.7 \pm 1.1$ & $0.5 \pm .07$ & 0.11 \\
$\quad$ year & & & \\
Visits to emergency room in & $1.1 \pm 1.6$ & $0.40 \pm 0.08$ & 0.02 \\
$\quad$ previous year & & & \\
\hline
\end{tabular}

Data presented as mean \pm SD unless otherwise indicated. COPD Chronic obstructive pulmonary disease; FEV ${ }_{1}$ Forced expiratory volume in $1 \mathrm{~s}$; SGRQ St George's Respiratory Questionnaire

12 months. A total of eight patients dropped out: three in the intervention group and five in the control group. One patient (control group) died from respiratory causes, and three were lost because they moved over the course of the study (two from the intervention group and one from the control group). Four patients (three from the control group) refused to complete the follow-up assessments. Those who dropped out of the study did not differ from the sample in any of the characteristics reported in Table 1 . Only patients with complete data (57 in the intervention group and 45 in the control group) were retained for analysis.

\section{Patient characteristics}

The demographic and medical characteristics of both groups were similar except for the number of ED visits in the previous year, which was lower in the control group. The subjects had an average smoking history of 40 pack-years, and an average of two medical comorbidities each (Table 1). Both groups had a moderate level of COPD-related disability.

\section{HRQoL}

The intervention subjects' HRQoL improved significantly at three months (total score $\mathrm{A}=-5.0[\mathrm{P}=0.006]$ ) and 12 months (total score $A=-6.7 ;[P<0.001])$, as evidenced by decreased scores on the SGRQ (within-group differences [Table 2]). In contrast, the SGRQ scores increased significantly in the control group at both three months (total score $\mathrm{A}=+3.7[\mathrm{P}=0.02]$ ) and at 12 months (total score $\mathrm{A}=+3.4$ $[\mathrm{P}=0.03])$. On examining the subscales, it is the global impact that appeared to be responsible for the improvements in the intervention group. The between-group difference at three and 12 months (total score $A=-6.0[P<0.001]$ ) and 12 months (total score $A=-11[P<0.001]$ ) were both higher (between-group differences [Table 2]).

\section{Hospitalizations, ED visits and COPD Knowledge Questionnaire} scores

Patients in the intervention group experienced a significant drop in the number of ED visits and hospitalizations between the one-year period before the educational program and the one-year period after the intervention. 
TABLE 2

Baseline differences in St George Respiratory Questionnaire (SGRQ) dimensions at different times in subjects with and without intervention

\begin{tabular}{|c|c|c|c|c|c|c|c|c|}
\hline & \multicolumn{8}{|c|}{ Within-group differences from baseline $(95 \% \mathrm{CI})$} \\
\hline & \multicolumn{4}{|c|}{ Intervention group $(n=57)$} & \multicolumn{4}{|c|}{ Control group $(n=45)$} \\
\hline & 3 months & $\mathbf{P}$ & 1 year & $\mathbf{P}$ & 3 months & $\mathbf{P}$ & 1 year & $\mathbf{P}$ \\
\hline \multicolumn{9}{|l|}{ SGRQ score } \\
\hline Symptoms & $-0.9(-3.7$ to 2.0$)$ & 0.70 & $-6.0(-9.5$ to -2.6$)$ & 0.002 & $3.1(-0.2$ to 6.3$)$ & 0.08 & $0.8(-3.2$ to 4.8$)$ & 0.63 \\
\hline Activity & $-1.8(-4.9$ to 1.4$)$ & 0.45 & $-3.9(-7.7$ to -0.1$)$ & 0.07 & $3.4(-0.2$ to 7.1$)$ & 0.05 & $1.9(-2.5$ to 6.2$)$ & 0.27 \\
\hline Impact & $-8.3(-11.7$ to -4.9$)$ & 0.001 & $-8.7(-12.5$ to -5.0$)$ & $<0.001$ & 4.2 (0.3 to 8.1$)$ & 0.09 & 5.0 (0.7 to 9.3$)$ & 0.018 \\
\hline \multirow[t]{3}{*}{ Total } & $-5.0(-7.6$ to -2.3$)$ & 0.006 & $-6.7(-9.9$ to -3.7$)$ & $<0.001$ & $3.7(0.7$ to 6.7$)$ & 0.022 & $3.4(0.1$ to 7.0$)$ & 0.032 \\
\hline & \multicolumn{4}{|c|}{ Between-group differences: Intervention minus control $(95 \% \mathrm{Cl})$} & & & & \\
\hline & 3 months & $\mathbf{P}$ & 1 year & $\mathbf{P}$ & & & & \\
\hline \multicolumn{9}{|l|}{ SGRQ score } \\
\hline Symptoms & $-4.8(-9.9$ to 2.5$)$ & 0.24 & $-7.4(-14.8$ to -0.7$)$ & 0.048 & & & & \\
\hline Activity & $-2.6(-11.5$ to -1.1$)$ & 0.017 & $-7.6(-13.6$ to -1.6$)$ & 0.014 & & & & \\
\hline Impact & $-8.6(-18.2$ to -7.3$)$ & $<0.001$ & $-14.8(-20.8$ to -8.7$)$ & $<0.001$ & & & & \\
\hline Total & $-6.0(-13.2$ to -4.9$)$ & $<0.001$ & $-11.0(-16.3$ to -5.8$)$ & $<0.001$ & & & & \\
\hline
\end{tabular}

Data presented as mean $(95 \% \mathrm{Cl})$, adjusted for sex, age and baseline values

TABLE 3

Hospitalizations and emergency room visits according to group for one year

\begin{tabular}{|c|c|c|c|c|c|c|}
\hline \multirow[b]{2}{*}{ Variable } & \multicolumn{3}{|c|}{ Intervention group $(n=57)$} & \multicolumn{3}{|c|}{ Control group $(n=45)$} \\
\hline & $\begin{array}{c}\text { 1-year } \\
\text { preintervention }\end{array}$ & $\begin{array}{c}\text { 1-year } \\
\text { postintervention }\end{array}$ & $\mathbf{P}$ & $\begin{array}{c}\text { 1-year } \\
\text { preintervention }\end{array}$ & $\begin{array}{c}\text { 1-year } \\
\text { postintervention }\end{array}$ & $\mathbf{P}$ \\
\hline Hospitalizations & $0.7 \pm 1.1$ & $0.3 \pm 0.9$ & 0.017 & $0.5 \pm 0.7$ & $0.5 \pm 0.9$ & $P>0.05$ \\
\hline Emergency room visits & $1.1 \pm 1.6$ & $0.2 \pm 0.6$ & 0.002 & $0.4 \pm 0.8$ & $0.4 \pm 0.9$ & $P>0.05$ \\
\hline
\end{tabular}

Data presented as mean \pm SD unless otherwise indicated

TABLE 4

COPD Knowledge Questionnaire scores

\begin{tabular}{lrlll}
\hline & Baseline & 4 weeks & 3 months & 12 months \\
\hline Intervention group $(n=57)$ & $57.5 \pm 12.6$ & $72.9 \pm 15.0^{\star \dagger}$ & $74.5 \pm 13.8^{\star \dagger}$ & $73.0 \pm 14.4^{* \dagger}$ \\
Control group $(n=45)$ & $57.6 \pm 15.0$ & $55.5 \pm 15.0$ & $64.1 \pm 14.0^{\star \ddagger}$ & $60.1 \pm 13.0$ \\
\hline
\end{tabular}

${ }^{*} P=0.0001$ versus baseline; ${ }^{\dagger} P=0.0001$ versus control; ${ }^{\ddagger} P=0.0001$ versus four weeks. COPD Chronic obstructive pulmonary disease

The number of hospitalizations dropped from $0.7 /$ person/year to $0.3 /$ person/year $(\mathrm{P}=0.017)$, and $\mathrm{ED}$ visits dropped from 1.1/person/year to $0.2 /$ person/year $(\mathrm{P}=0.002)$ (Table 3$)$. In contrast, the 45 subjects in the control group who were available for follow-up one year after entering the study did not experience a decrease in the number of ED visits or hospitalizations for COPD.

Furthermore, intervention subjects yielded significantly higher COPD Knowledge Questionnaire scores compared with the control patients at three and 12 months after study entry (Table 4).

\section{DISCUSSION}

The demographic and medical characteristics of both groups were similar (Table 1), except for the number of ED visits in the previous year, which was lower in the control group. This may be explained by the fact that they were not recruited following an ED visit or hospitalization for COPD, which was the case for many of the participants in the intervention group.

The findings of the present study showed significant effects of the educational intervention on patients' perceived HRQoL and knowledge about COPD. This suggests that a structured patient self-management education program can offer patients an opportunity to increase their confidence in their own ability to manage or avoid breathing difficulties while still enabling them to engage in routine activities. In turn, increasing an individual's level of confidence may assist them in performing daily activities more frequently, which may explain why it is the global impact subscale that improved the most following the intervention.
Education about self-treatment of exacerbations through the development and use of a written action plan also reduced hospitalizations and ED visits significantly compared with the control group. Bourbeau et al (10) showed that a disease-specific, self-management intervention including a patient education program, monthly telephone follow-up interviews and a simple home exercise program significantly reduced SGRQ global impact subscale scores and total SGRQ scores at four months. The current study also showed a reduction of $39.8 \%$ in the number of hospitalizations at 12 months, and a $41 \%$ reduction in the number of ED visits compared with the control group. The reduction in the number of hospitalizations was comparable with the results reported in the study by Bourbeau et al, while our reduction in the number of ED visits was superior to other published findings. One explanation may have been our strict definition of ED visits (ie, ED visits had to be shorter than $24 \mathrm{~h}$ ), thus bringing our rate of ED visits very low, with any visit of a longer duration being categorized as a hospitalization.

The inconsistencies between the present findings and those of previous studies could also be explained by the nonrandomized nature of our study and the risks inherent in comparing two differents groups. Finally, we hypothesize that the exceptionally motivated asthma educators in our study may have been partly responsible for the findings, potentially making the results difficult to reproduce in the future.

\section{Limitations}

One significant limitation of the present study was its nonrandomized design. As such, the educational program could have selected the most motivated patients. Moreover, we can argue that the intervention group showed higher levels of hospital use and ED visits before the trial; consequently, they were more likely to respond with decreases in these events than the control group. Despite this limitation, however, the present study has shown that an affordable self-management program in COPD can be effective for improving HRQoL (in the intervention group compared with the control group), and that this improvement could persist even at 12 months. Medication adherence was not assessed in the current study, and could have been better in 
the intervention group relative to the control group. This possibility could have, at least in part, accounted for the improved outcomes.

We also limited our conclusion to patients with moderately severe COPD because that was the category of patient included in the present study.

Despite the above limitations, the present study was strengthened by the fact that this was one of the first that attempted to separate the effect of education alone from the effect of a more complete program that included exercise and/or counselling by a case manager.

\section{CONCLUSION}

A planned education program is effective at improving the HRQoL, and in decreasing the number of ED visits and hospitalizations in COPD patients. The improvement of HRQoL persists after one year. Randomized research will still be needed to formulate clear recommendations regarding the form and contents of self-management education programs in COPD.

\section{REFERENCES}

1. O'Donnell DE, Hernandez P, Kaplan A, et al. Canadian Thoracic Society recommendations for management of chronic obstructive pulmonary disease: 2008 update - highlights for primary care. Can Respir J 2008;(15 Suppl A):1A-8A.

2. Rabe KF, Hurd S, Anzueto A, et al. Global strategy for the diagnosis, management, and prevention of chronic obstructive pulmonary disease: GOLD Executive Summary. Am J Respir Crit Care Med 2007;176:532-55.

3. Lacasse Y, Goldstein R, Lasserson TJ, Martin S. Pulmonary rehabilitation for chronic obstructive pulmonary disease. Cochrane Database Syst Rev 2006;4:CD003793.

4. Gross N, Levin D. Primary care of the patient with chronic obstructive pulmonary disease - part 2: Pharmacologic treatment across all stages of disease. Am J Med 2008;121:S13-S24.

5. Radin A, Cote C. Primary care of the patient with chronic obstructive pulmonary disease - part 1: Frontline prevention and early diagnosis. Am J Med 2008;121:S3-S12.

6. Nici L, Donner C, Wouters E, et al. American Thoracic Society/ European Respiratory Society Statement on Pulmonary Rehabilitation. Am J Respir Crit Care Med 2006;173:1390-413.

7. Rabe KF, Beghe B, Luppi F, et al. Update in chronic obstructive pulmonary disease, 2006. Am J Respir Crit Care Med 2007; 175:1222-32.
Practice implications

Self-management programs must be integrated in the usual care of patients with COPD.

All patient/personal identifiers were removed or anonymized so the patients/person(s) described cannot be identified through the details of the article.

CONFLICTS OF INTEREST: Dr Manon Labrecque, Mr K Rabhi, Mrs C Laurin, Mrs H Favreau, Mr Gregory Moullec and Dr K Lavoie have no actual or potential conflict of interest regarding organization(s) with financial interest in the subject matter.

ACKNOWLEDGEMENTS: The authors gratefully acknowledge GlaxoSmithKline for their support of the program; the educators: Lucie Jolicoeur, Suzanne Valois and Bernadette Tardivelle; the administrative coordinator Caroline Riopel; Khadija Mamouni for statistical analysis; and James Hatch for revision of the manuscript.

8. ZuWallack R, Hedges H. Primary care of the patient with chronic obstructive pulmonary disease - part 3: Pulmonary rehabilitation and comprehensive care for the patient with chronic obstructive pulmonary disease. Am J Med 2008;121:S25-S32.

9. Effing T ME, van der Valk PD, van der Palen J, et al. Self-management education for patients with chronic obstructive pulmonary disease. Cochrane Database Syst Rev 2007;17(4):CD002990.

10. Bourbeau J, Julien M, Maltais F, et al. Reduction of hospital utilization in patients with chronic obstructive pulmonary disease: A disease-specific self-management intervention. Arch Intern Med 2003;163:585-91.

11. Celli BR, MacNee W; ATS/ERS Task Force. Standards for the diagnosis and treatment of patients with COPD: A summary of the ATS/ERS position paper. Eur Respir J 2004:23:932-46 (Erratum 2006;27:242).

12. Fabbri LM, Pauwel RA, Hurd SS. Global strategy for the diagnosis, management, and prevention of chronic obstructive pulmonary disease: GOLD Executive Summary updated 2003. COPD 2004;1:105-41.

13. Anthonisen NR, Manfreda J, Warren CP, Hershfield ES, Harding GK, Nelson NA. Antibiotic therapy in exacerbations of chronic obstructive pulmonary disease. Ann Intern Med 1987;106:196-204.

14. Jones P. A self-complete measure of health status for chronic airflow limitation. The St. George's Respiratory Questionnaire. Am Rev Respir Dis 1992;145:1321-7. 


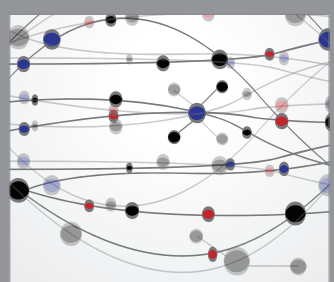

The Scientific World Journal
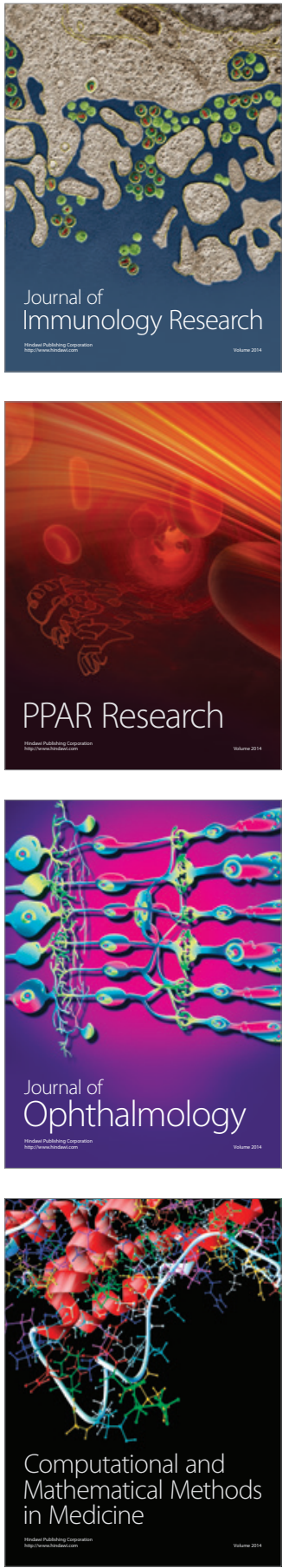

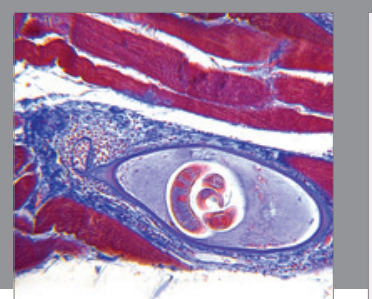

Gastroenterology Research and Practice

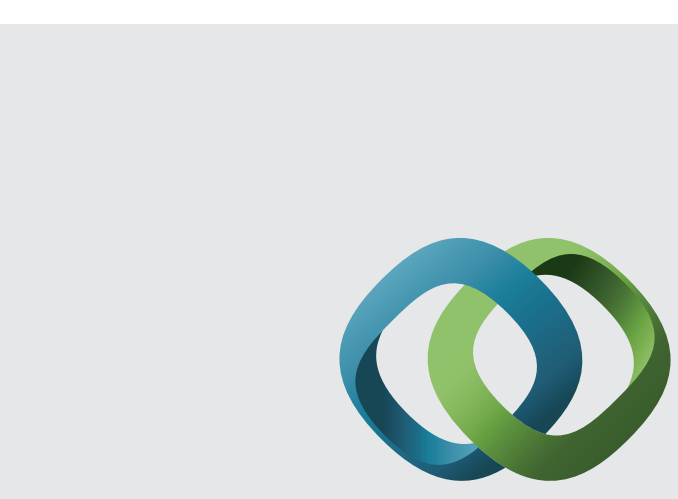

\section{Hindawi}

Submit your manuscripts at

http://www.hindawi.com
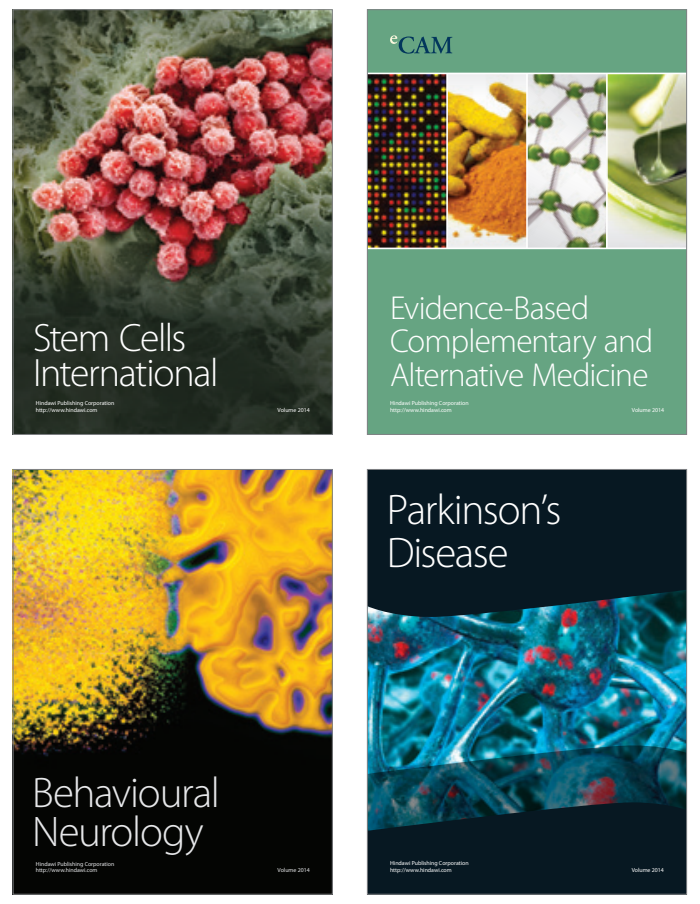
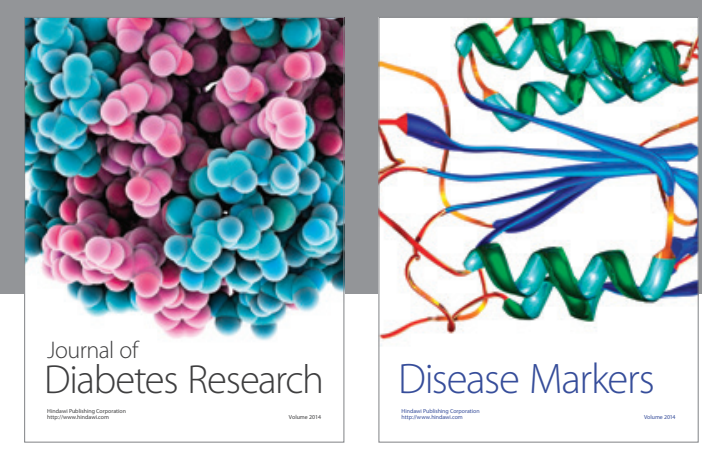

Disease Markers
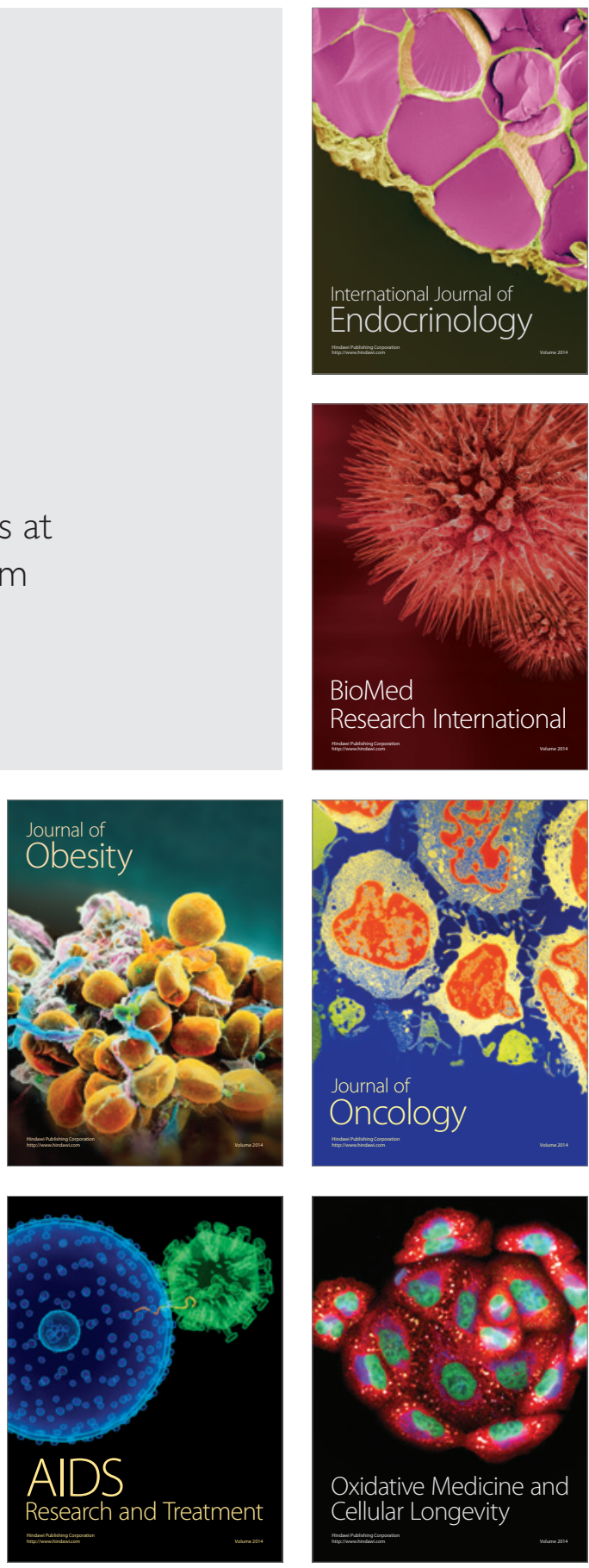